\title{
DISEÑO DE UN INSTRUMENTO DE MEDICIÓN MULTIDIMENSIONAL DEL VALOR PERCIBIDO ESTUDIANTIL DEL SERVICIO DE CLASES
}

\section{Oscar Álvaro Valdivieso Taborga}

\section{RESUMEN}

El propósito del artículo es el diseño de un instrumento multidimensional del valor percibido del servicio de clases en la industria de servicios de la educación superior. Para el efecto, primero se realizó una revisión de literatura acerca de la medición del valor percibido del servicio por el cliente, encontrándose los siguientes resultados: el concepto del valor percibido es dinámico, abstracto y multifacético, presentando dos conceptualizaciones (la utilitaria y la sociopsicológica) y tres enfoques para su medición (medida global de un solo ítem, global unidimensional con múltiples ítems y multidimensional). Asimismo se describieron los constructos antecedentes del valor (calidad de servicio, precio monetario, riesgo percibido, conveniencia, precio comportamental, respuesta emocional y reputación) y sus consecuencias (satisfacción e intenciones de comportamiento). Siguiendo la metodología propuesta por Martínez [46], se diseñó un instrumento de medición del valor para el servicio específico de clases universitarias con validez de contenido, creando, modificando y adecuando ítems a partir de baterías propuestas por diferentes investigadores y el juicio de expertos. La batería diseñada contiene 50 ítems distribuidos en siete dimensiones (Valor funcional, social, emocional, epistémico, por el dinero, reputación e imagen, y sacrificios). Por último, a partir del modelo comprehensivo propuesto por Valdivieso [75], se proponen investigaciones futuras utilizando el instrumento diseñado del valor percibido.

Palabras Clave: Valor Percibido del Servicio de Clases, Medida Multidimensional del Valor Percibido, Instrumento de Medición, Evaluación del Servicio de Clases, Modelo Comprehensivo. 